\title{
Habitat suitability for juvenile common sole (Solea solea, L.) in the Bay of Biscay (France): A quantitative description using indicators based on epibenthic fauna
}

\author{
Olivier Le Pape ${ }^{a,{ }^{*}}$, Loîc Baulier ${ }^{a}$, Aurélie Cloarec ${ }^{a}$, Jocelyne Martin ${ }^{b}$, François Le Loc' $h^{c}$ and Yves \\ Désaunay ${ }^{\mathrm{b}}$
}

\author{
${ }^{a}$ Département Halieutique, Agrocampus Rennes, 65 rue de St Brieuc, CS 84215, 35042 Rennes \\ Cedex, France \\ ${ }^{\mathrm{b}}$ IFREMER, EMH, rue de l'Ile d'Yeu, B.P. 21105, 44311 Nantes Cedex, France \\ 'IRD, UR RAP, Centre de Recherche Halieutique, Avenue Jean Monnet, B.P. 171, 34203 Sète Cedex, \\ France \\ *: Corresponding author : Olivier.Le_Pape@agrocampus-rennes.fr
}

\begin{abstract}
:
This study describes the spatial distribution of young-of-the-year common sole based on beam trawl surveys conducted in late summer in the coastal and estuarine parts of the Bay of Biscay (France). Previous studies showed that habitat suitability for juvenile common sole varies according to physical factors and notably bathymetry and sediment structure. Nevertheless, the use of these descriptors alone to model habitat suitability led to considerable unexplained variability in juvenile common sole distribution. Hence, the epibenthic macro- and megafauna collected during beam trawl surveys was taken into account to improve models of habitat suitability for these juvenile flatfish. Ecotrophic guilds based on life traits (behaviour, mobility and feeding) were used to develop generic indicators of trawled benthic fauna. These synthetic descriptors were used in generalized linear models of habitat suitability in order to characterize the distribution of juvenile common sole. This approach significantly improved the description based on physical descriptors and allowed demonstrating that young common sole distribution is related to the density of trawled deposit and suspension feeders and also of carnivorous organisms. These models provide a reliable method to develop indicators of nursery habitat suitability from trawl survey data with the aim of assessing and surveying their quality.
\end{abstract}

Keywords: Solea solea; Nursery ground; Habitat suitability models; Epibenthic fauna; Ecotrophic guilds; Bay of Biscay 


\section{Introduction}

Coastal and estuarine systems are highly productive areas that serve as nursery grounds for many marine species of commercial importance, widely distributed on the continental shelf (Beck et al., 2001; Peterson, 2003), and particularly flatfish (Van der Veer et al., 2000a). Hence, the available area and the quality of coastal and estuarine habitats have a considerable influence on recruitment level (Rijnsdorp et al., 1992; Gibson, 1994). Nevertheless, human pressure is especially high in these areas and the natural communities may be threatened. If juveniles are confined within coastal and estuarine habitats, recruitment level and population size could be affected by habitat loss, nutrient excess or pollution loading (Johnson et al., 1998; Peterson et al., 2000). Protecting these habitats is essential, so there is a need to determine optimal habitats to support decision making for their management (Rubec et al., 1999; Beck et al., 2001). Therefore it is important to search for integrated ecological indicators for the assessment of environmental quality, in relation to fish habitat function (Adams, 2002; Whitfield and Elliott, 2002).

Inshore waters of the Bay of Biscay (west coast of France) support nursery areas for several commercially important species, especially the common sole (Dorel et al., 1991). Mature common sole constitute an offshore population that spawns in late winter. Postlarval stages reach inshore areas in spring where they continue to grow for about two years (Koutsikopoulos et al., 1989). The main nursery areas for the common sole have been clearly identified in the Bay of Biscay from an approach based on physical descriptors, coupling a statistical model of habitat suitability with a geographic information system (Le Pape et al., 2003): they are located in shallow soft bottom areas of estuarine and semienclosed parts of the coast. Nevertheless, the use of only physical descriptors to model the distribution of young of the year (y-o-y) common sole led to considerable non-explained variability (> 70\%). Moreover, these models did not allow assessing nursery quality.

To develop reliable indicators of the nursery function, the use of the benthic fauna appears to provide opportunities for several reasons (Peterson et al., 2000):

o First, spatial distribution and fluctuations of abundance of juvenile flatfish are related to the quality of the invertebrate benthic community which constitutes their food supply (Gibson, 1994). Especially, young flatfish prefer habitats offering substrate with high densities of polychaetes and bivalves (Rogers, 1992; Cabral and Costa, 1999; McConnaughey and Smith, 2000).

o Second, other processes affecting growth and mortality of juvenile flatfish can be related to benthic fauna: Predation, an important controlling factor of juvenile flatfish density (Van der Veer et al., 2000b), depends on the associated fauna (Ross, 2003). On the other hand, Le Pape et al. (2004) have emphasised the negative role of an invasive mollusc, the slipper limpet (Crepidula fornicata, L.), on habitat structure for the juvenile common sole.

o Third, benthic fauna is an indicator of environmental quality (Grall and Glémarec, 1997b; Salas et al., 2004) and can, independent of any direct relation with juvenile fishes, be used to describe nursery habitat in coastal areas (Sheridan and Minello, 2003).

The purpose of the present study was to estimate the relation between epibenthic macro- and megafauna (E-M-MFauna) collected during beam trawl surveys and spatial distribution and abundance of juvenile common sole on nursery grounds in the Bay of Biscay. Relations were studied between physical features known to influence the distribution of juvenile common sole (bathymetry and sediment texture), composition and abundance of trawled E-M-MFauna, described with ecotrophic guilds, and indice of y-o-y density. Generalised linear models were used to analyse habitat suitability for $y-0-y$ and especially to consider the relevance of descriptors based on E-M-MFauna as indicators of nursery function. 


\section{Materials and methods}

\subsection{Beam trawl survey data}

From 2000 to 2003, four independent coastal beam trawl surveys (191 trawl hauls) were undertaken (IFREMER, RV 'Gwen Drez') from the end of August to the end of September throughout six different coastal areas located in the central part of the Bay of Biscay (three semi-enclosed bays and three estuaries, Fig. 1), known as important nursery grounds for common sole (Le Pape et al., 2003). As common sole nursery grounds are located in shallow soft bottom areas, these surveys were concentrated inside the $10 \mathrm{~m}$ isobath and outside rocky grounds. The sampling scheme per investigated coastal sector involved strata of homogeneous depth (Le Pape et al., 2003). The beam trawl opening used was $2.9 \mathrm{~m}$ wide and $0.50 \mathrm{~m}$ high, and the net had $20-\mathrm{mm}$ stretched mesh in the codend. The trawl had no tickler chain ahead of the foot rope. Hauls were made only in daylight and performed at 2.5 knots for 15 min.

The season (end of summer) was chosen for two reasons:

- Before the first autumnal migration (Dorel et al., 1991), the distribution of y-o-y is representative of the productive period and is appropriate to describe the nurseries.

- With the trawl mesh used ( $20 \mathrm{~mm}$, large enough to limit collapse by benthic fauna), in this period of the year, there are limited problems of selectivity and size-dependent catchability for y-o-y born six months before (average length reaching $11 \mathrm{~cm}$; Gilliers et al., in press).

All common soles caught were counted, weighted and measured, and age groups were established after otolith reading. Catch per unit effort (CPUE) for $y-0-y$ were calculated for each trawl haul (number of $y-0-y$ caught ha ${ }^{-1}$ ) and used as indice of $y-0-y$ density. At the same time, all trawled E-M-MFauna invertebrate taxa were identified, counted and weighted, apart from Cnidaria and Ascidea, which (because they were very rarely caught) were considered accidentally sampled and therefore not taken into account.

\subsection{Additional descriptors}

\subsubsection{Physical descriptors}

Information on the physical variables, allocated to each trawl haul, was taken from a bathymetry map (Service Hydrographique et Océanographique de la Marine, France, scale: $1 / 500000$ ) indicating the coastline and isobaths of 5 and $10 \mathrm{~m}$ and a sediment structure map (Bureau de Recherches Géologiques et Minières, France, scale: 1/500 000) showing two classes of sediment: mud and sand.

\subsubsection{Life traits, descriptors of trawled epibenthic fauna}

Additional descriptors were associated to the epibenthic invertebrate taxa caught during the surveys to provide information on their biology and ecology, according to the method of ecotrophic guilds (Bonsdorff and Pearson, 1999; Frid et al., 2000; Luckzovitch et al., 2000). Three ecological/biological traits of E-M-MFauna were identified a priori from adult behaviour (feeding habit, mobility, relation with the sea bottom). Each of these three traits was divided into several categories, called functional groups:

1. feeding habit or trophic group (five different functional groups): carnivorous (predator), deposit feeder, suspension filter feeder, grazer (herbivorous and micrograzer), necrophagous (scavenger).

2. mobility (four functional groups): none, low, medium, high.

3. relation with the sea bottom (three functional groups): sessile-burrower (including crevice-dweller), crawler-walker, swimmer. 
Each species caught during the surveys was allocated in one functional group of each biological trait (Table 1). This classification was based on literature, especially Grall and Glémarec (1997a) and Hily and Bouteille (1999), and from specialist knowledge.

\subsection{Synthetic variables based on ecotrophic guilds to quantify trawled epibenthic fauna}

Le Pape et al. (2004) have emphasised the negative effect of the slipper limpet on juvenile common sole density, consistent with structural changes in the benthic habitat caused by slipper limpet colonies. Hence, this invasive mollusc was previously discriminated from the other taxa and analysed as a separate descriptor.

In each trawl haul, for E-M-MFauna, different taxa were were pooled to obtain one number of individuals caught by functional group. Next, for each trawl haul, CPUE by group were calculated (number of individuals caught per hectare, considered an indice of density). These indices describe the biological richness, independently of the species which display these characteristics. Finally, these CPUE were natural log-transformed, after a preliminary transformation (Eq. 1), to include some rare null data:

$$
\ln (\text { func. group }+1 \text { ) }
$$

where func. group is the CPUE of trawled epibenthic invertebrates in one group. This resulted in a trawl haul by functional group table, filled with log-transformed CPUE.

\subsection{Preliminary analysis of data on trawled benthic invertebrates}

The aim of the study was to use variables based on E-M-MFauna to describe the CPUE of juvenile common sole with linear models. In such models, when covariates are correlated, their significance is compromised (Graham, 2003) to explain their relative importance and to identify factors that might modulate habitat clustering (Maravelias, 2001). Hence, a preliminary analysis was necessary to study the correlation between biological traits and between functional groups inside these traits and then to build non-correlated synthetic descriptors of E-M-MFauna.

\subsection{Habitat suitability models for juvenile common sole}

Y-o-y CPUE were characterized by a large number of zero and some rare very high values. Such a distribution avoids the use of a simple linear approach to model these data (Le Pape et al., 2003). Hence, the model used here assumed a delta distribution for juveniles, coupling a binomial sub-model, testing for the presence of $y-0-y$, with a distribution for CPUE when y-o-y were present (Stefansson, 1996). Hence, two sub-models were initially developed and then linked to investigate habitat suitability.

In the first sub-model, the presence of $y-0-y$ was described with a binomial model:

$$
\text { YOY } \left._{0 / 1} \approx \text { factor(nursery } \times \text { bathymetry } \times \text { sediment }\right)+ \text { covariate }(\ln (\text { func. group }+1))+\varepsilon 0 / 1
$$

or

$\mathrm{YOY}_{0 / 1} \approx$ factor $($ bathymetry $\times$ sediment $)+$ covariate $(\ln ($ func. group $)+1)+\varepsilon 0 / 1$

where $Y_{0} Y_{0 / 1}$ is the Boolean value for y-o-y (0 if no y-o-y were caught, 1 otherwise), i.e. the response variable of the GLM fitted to a binomial distribution and a logit link. factor (nursery $\times$ bathymetry $\times$ sediment) is a single categorical descriptor for the nursery sector, the bathymetric class and the sediment structure. This single factor allows a 
description of physical habitat suitability and takes into account the geographical variability between nursery sectors (Eq. 2). Another descriptor, factor(bathymetry×sediment), was also tested in an alternative sub-model (Eq. 3) in which the geographical variability is not included. covariate(ln(functional group +1$))$ is the log-transformed value of the indice (CPUE) of E-M-MFauna cluster-density. This log-transformation avoids rare hauls in which the E-MMFauna's CPUE by functional groups was very high from driving the model. $\varepsilon_{0 / 1}$ is the residual (error term).

Next a second sub-model was developed for positive y-o-y CPUE values:

$\ln \left(\mathrm{YOY}_{+}\right) \approx$ factor(nursery $\times$ bathymetry $\times$ sediment $)+$ covariate $(\ln ($ func. group +1$))+\varepsilon_{+}(4)$

or

$\ln \left(\mathrm{YOY}_{+}\right) \approx$ factor(bathymetry $\times$ sediment $)+$ covariate $(\ln ($ func. group $)+1)+\varepsilon_{+}$

where $\mathrm{YOY}_{+}$is the value for $y-0-y$ CPUE (no. of fish ha ${ }^{-1}$ ) when these juveniles are present (data from trawl hauls with at least one caught $y-0-y$ ). The natural logarithm of $Y O Y_{+}$is the response variable of this GLM fitted to a Gaussian distribution and an identity link. Preliminary tests on data distribution showed that these were the best options to describe the log-normal distribution of these positive values (Le Pape et al., 2003).

Finally, the 2 sub-models were combined to estimate habitat suitability for y-o-y (Eq. 6), including its associated error (Eq. 7):

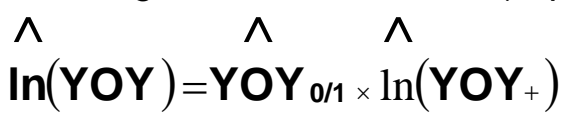

$$
\hat{\sigma}\left(\ln \left(\mathrm{YOY}_{\mathrm{O}}\right)=\sqrt{\left.\left(\hat{\mathrm{YOY}}_{\mathrm{O} / 1}\right)^{2} \times\left(\hat{\sigma} \ln \left(\mathrm{YOY}_{+}\right)\right)\right)^{2}+\left(\hat{\sigma}\left(\mathrm{YOY}_{0 / 1}\right)\right)^{2} \times\left(\hat{\left.\ln \left(\mathrm{YOY}_{+}\right)\right)^{2}}\right.}\right.
$$

$\wedge$

where $\ln ($ YOY $)$ is the logarithm of $y-0-y$ CPUE, estimated with the delta method combining $\wedge$

the two submodels and $\sigma(\ln ($ YOY $))$ is the associated standard error of estimation. $Y O Y_{0 / 1}$ is the probability of presence, as estimated by the binomial model, and $\ln \left(\mathrm{YOY}_{+}\right)$is the logarithm for the CPUE of $y-0-y$ when present, as estimated by the log-normal positive model.

The formulation allows the effect of E-M-MFauna on y-o-y distribution to be modelled accounting for the influence of physical descriptors, with (Eqs. 2 and 4) or without (Eqs. 3 and 5) taking into account the heterogeneity between nursery sectors. Alternative models, using only covariates related to E-M-MFauna, with several covariates related to different functional groups, or with an additional descriptor related to slipper limpets CPUE, were also tested.

\section{Results}

\subsection{Preliminary analysis on E-M-MFauna}


Correlation between functional groups (Table 2) demonstrated the redundancies between the three guilds; the taxa were pooled similarly in the three classifications and can be synthesised in four distinct classes: (1) carnivorous, crawler-walker and low mobility, (2) deposit feeder and suspension filter feeder, sessile-burrower, no mobility, (3) necrophagous and medium mobility, and (4) swimmer and high mobility.

As groups from different guilds were built from the same data (CPUE per taxa) and correlated, they cannot be used together as descriptors in models. Hence, it was necessary to choose one guild whose functional groups can be tested as descriptors of $y-0-y$ distribution. The trophic group was the selected biological trait: more informative than the others with regard to the functionality of the benthic system, it appeared to be the most appropriate. Moreover, there were also significant correlations between functional groups inside biological traits (Table 2). Therefore the deposit and suspension filter feeders were combined in a single group, representing the trawled benthic invertebrates that feed on detrital or planktonic organic matter.

\subsection{Habitat suitability models including trawled invertebrates}

The four trophic groups kept after the preliminary analysis of correlations (carnivorous, deposit-suspension feeders, grazers, necrophagous) were first tested separately to analyse their relation with y-o-y. Two of these four functional groups appeared well related to both y-o-y presence and density indice (Table 3): deposit-suspension feeders and carnivorous. Y-o-y are more often present and are more numerous when present where the CPUE of these trophic groups are high.

Habitat suitability models using both physics and the two groups of E-M-MFauna related to y-o-y (Table 3) were subsequently developed. The analysis of the log-normal positive model demonstrated that there was no trend in the residuals (Fig. 2) and this formulation appeared reliable to develop habitat suitability models for $y-0-y$.

Separate analysis of the two sub-models confirms the effects of the physical descriptors (Table 4): Presence (binomial model) and abundance (positive model) decreased with increasing depth and granule size. Moreover, the use of the geographic component in the physical descriptor strongly improves the model fit; $y-0-y$ presence and CPUE were very different from one nursery sector to another.

Some results related to the use of 2 E-M-MFauna descriptors were also apparent from these models (Table 4). Except for the additional effect of the deposit-suspension feeders on Eq. (2), these descriptors were significant for the binomial and the positive models. Both models, with or without the geographic sector in the first factor, were significantly improved by adding a covariate related to one or the other of the two trophic groups studied. Areas covered with high densities of deposit-suspension feeders and/or carnivorous invertebrates appeared to shelter higher densities of y-o-y (Fig. 3). For example, when all the surveys were pooled (six sectors and four years), on very shallow $(<5 \mathrm{~m})$ muddy grounds, the best nursery areas for $y-0-y$, the average $y-0-y$ CPUE was only 3 ind $\mathrm{ha}^{-1}$ when the CPUE of deposit-suspension feeders was low $\left(<10\right.$ ind ha ${ }^{-1}$, lower quartile), but reached 200 y-o-y ha ${ }^{-1}$ when deposit-suspension feeders CPUE were abundant $(>2500$ ind ha ${ }^{-1}$, higher quartile).

Another statement comes from the comparison between the two models, with or without the nursery sector. When the variables describing E-M-MFauna by trophic group were taken into account, the model including geographic information $(\approx 45 \%$ of explained deviance in average; Table 4) was still better than the alternate model $(\approx 30 \%)$. Nevertheless, the information added by the trophic groups was higher when the geographic information was not included. This looked as if the differences between nursery sectors were partly explained by covariates related to E-M-MFauna.

Other models were analysed for further investigation on habitat suitability of $y-0-y$. First, the other two trophic groups of benthic invertebrates were added to models including 
physical descriptors without significant results. Second, multiple models using simultaneously one factor representing the physical habitat and two covariates related to deposit-suspension feeder and carnivorous were tested but did not give any significant results. Third, models including slipper limpet CPUE in the description as an additional variable to physical factor and E-M-MFauna were also tested. Trawls hauls where slipper limpets are present are scarce at the scale of the Bay of Biscay and this additional variable did not provide any significant improvement of the model. On the other hand, the same entire modelling approach was conducted on trawled biomass of benthic invertebrates ( $\left.\mathrm{kg} \mathrm{ha}^{-1}\right)$ instead of trawled density. Results were similar and did not provide any additional information.

\section{Discussion}

\subsection{The use of ecotrophic guilds on E-M-MFauna to build descriptors of habitat}

An alternative to the method of ecotrophic guilds would have been to use CPUE of invertebrates per taxa to study the relation between E-M-MFauna and y-o-y distribution: a factorial correspondence analysis followed by a hierarchical ascending classification allows building faunistic groups of benthic invertebrates (Grall and Glémarec, 1997b), and the use of CPUE in these groups as descriptors. Such a method was tested to study y-o-y habitat suitability (Baulier, pers. comm., ) and demonstrated the correlation between CPUE of some faunistic groups and CPUE of $y-0-y$ in the Vilaine Bay (link between some abundant bivalve species and nursery grounds). Nevertheless, with regard to ecotrophic guilds, such an approach faced with several problems limiting its use to develop indicators:

First, if they are useful to describe fauna compounds in nearshore marine habitats (Sheridan and Minello, 2003), faunistic groups built from clustering methods are specific to one analysis. Consequently, they cannot be generalized as indicators.

Second, when this method is used on a large scale (i.e. Bay of Biscay), it dissociates faunistic groups according to species substitution in relation to biogeographic distribution (Souissi et al., 2001). Such a partition is the result of species response to large-scale patterns, and especially temperature (Martino and Able, 2003), and is not appropriate for the development of indicators of fish habitat suitability.

On the contrary, ecotrophic guilds take into account the fact that different species perform similar ecological roles at different locations (Hooper et al., 2005). The biological trait approach is resistant to biogeographic variations and highlight different assemblages, related to ecosystem functioning and production (Bolam et al., 2003; Bremmer et al., 2003).

The advantages of ecotrophic guilds as robust indicators of nursery habitat suitability was demonstrated by Morin (pers. comm., ) in the Seine estuary (Fig. 1), another nursery ground for the common sole, on a different stock population: the same method selected the same descriptors of nursery suitability (CPUE of deposit-suspension feeder and carnivorous).

\subsection{The interest of habitat suitability models including E-M-MFauna}

In previous studies, y-o-y appeared to be concentrated in shallow areas, covered with fine sediment (Gibson, 1994), especially in the Bay of Biscay (Le Pape et al., 2003). The present study demonstrated that the additional use of E-M-MFauna descriptors significantly improve this description: $y$-o-y are more often present and more numerous where densities of benthic invertebrates that feed on detrital or planktonic organic matter and/or of carnivorous are high.

\subsubsection{Additional information provided by E-M-MFauna descriptors, a causal relation?}

As a link between benthic fauna and nursery function has been demonstrated (several syntheses in Gibson, 1994; Peterson et al., 2000; Beck et al., 2001; Adams et al., 2004), our correlations appear logical: First, concentration of juvenile fishes in coastal and estuarine areas is partly due to the abundance of prey (Blaber and Blaber, 1980), and, 
especially to young stages of polychaetes and bivalves (deposit-suspension feeder) for the common sole (Amara et al., 2001; Darnaude et al., 2001). Second, niche overlap, competition and predation between carnivorous, very abundant in nursery areas, have been demonstrated (Peterson, 2003; Van der Veer et al., 2000b).

Nevertheless, the present study cannot be used to analyse ecological links between benthos and young fishes. Beam trawl data provide only a restricted sample of benthic fauna, biased in favour of large epibenthic species (Jennings et al., 1999). Especially, as young stages of polychaetes and bivalves are too small and too linked to the substrate to be estimated with a trawl, furthermore with a $20 \mathrm{~mm}$ mesh net size, these data are not appropriate to quantify food availability for young fishes. However, trawl surveys can be used to develop indicators of the E-M-MFauna (Jennings et al., 1999; Frid et al., 2000) and to describe nursery habitat suitability with statistical models, without analysing causality in the relations.

\subsubsection{Advantages of E-M-MFauna indicators to describe nursery habitat suitability}

A main way to describe fish habitat suitability consists in building indice with multivariate models using environmental factors as descriptors (Norcross et al., 1999; Power et al., 2000). With covariates based on E-M-MFauna, it is possible to improve the description: First, juvenile flatfish prefer sheltered parts of the coast and embayments (Pihl and Van der Veer, 1992; Le Pape et al., 2003). As there is a link between coastal exposure and benthic assemblages on a mesoscale (Jordan et al., 2005), the differences in y-o-y distribution between nursery sectors are partly explained by covariates related to E-M-MFauna.

Second, small-scale variability occurs in juvenile flatfish distribution (Rogers, 1992; Allen and Baltz, 1997) and physical descriptors do not account for it (Le Pape et al., 2003). Additional deviance brought by E-M-MFauna descriptors in models including geographic sectors leads to the conclusion that these covariates improve habitat description locally (Stoner et al., 2001).

Hence, descriptors of the trawled epibenthic fauna improve the models of habitat suitability both on meso and local scales. Moreover, these models allow some new perspectives: a model based on physical factors does not take into account the degradation of habitat quality caused by anthropogenic pressure, pollution or eutrophication. On the contrary, benthic fauna descriptors allow considering such degradation (Grall and Glémarec, 1997b; Salas et al., 2004).

On the other hand, synthetic descriptors of the trawled E-M-MFauna may be useful in data-poor environment. Temporal variations of fish density are very important in coastal and estuarine areas (Van der Veer et al., 2000a; Attril and Power, 2002). It is therefore necessary to use large standardized time series to provide a reliable diagnosis on habitat suitability from data on fish densities. Synthetic variables based on a large number of benthic species smooth interannual variations and allow a reliable diagnosis with shorter series to be reached.

Furthermore, when fish populations are depleted, it becomes difficult to analyse habitat suitability with regard to fish density. If stock size declines, the spatial distribution of the population and the spread of colonized nurseries (Hugues et al., 2005) may be reduced. The use of models based on E-M-MFauna, validated in areas where fish is abundant, would allow estimating a potential habitat functionality elsewhere.

Hence, the use of trawled invertebrates to estimate habitat suitability for juvenile fish provides opportunities for nursery quality assessment. As the associated trawled benthic fauna is useful to study the impact of fishing (Jennings et al., 1999; Frid et al., 2000), it appears appropriate for the study of nursery habitats. In this context, a more basic protocol for the quantification of trawled benthic organisms, consisting in a count/weight of invertebrate by functional group, easier to collect, would probably simplify the protocol.

\subsection{Towards integrated approaches coupling benthic fauna and juvenile fishes}

One complementary approach to the present study would be to couple data from specific surveys of benthic fauna, conducted with gears adapted to estimate the density of 
benthic and endobenthic organisms (i.e. grabs; Grall and Glémarec, 1997a, b), with trawl survey data for juvenile fishes. Comparable approaches have already provided fruitful results for the study of fishing effects (Blanchard et al., 2004). This method would allow studying the ecological link between benthos and young fishes (Darnaude et al., 2004), and providing nursery suitability models. Beck et al. (2001) point out the need for developing such integrated research plans to improve the understanding of the role of nearshore ecosystems as fish nurseries and the assessment of essential fish habitats.

Emerging monitoring systems for the protection of coastal waters and habitats (Basset and Abbiati, 2004) take into account the ecological function to complete the assessment based on water quality (Coates et al., 2004). Invertebrates are included in these monitoring networks to map benthic assemblages (Jordan et al., 2005). If models linking suitability for juvenile fish to descriptors of the benthic fauna are validated, these tools will potentially allow the creation of distribution maps of nurseries (Le Pape et al., 2003) so that these essential fish habitats can be assessed.

\section{Acknowledgments}

This project was supported by the French National Programme for Coastal Ecology. The authors are grateful to Jocelyne Morin (IFREMER) for discussions about comparable results in the Bay of Seine. We would also like to thank the anonymous reviewers for their fruitful suggestions. 


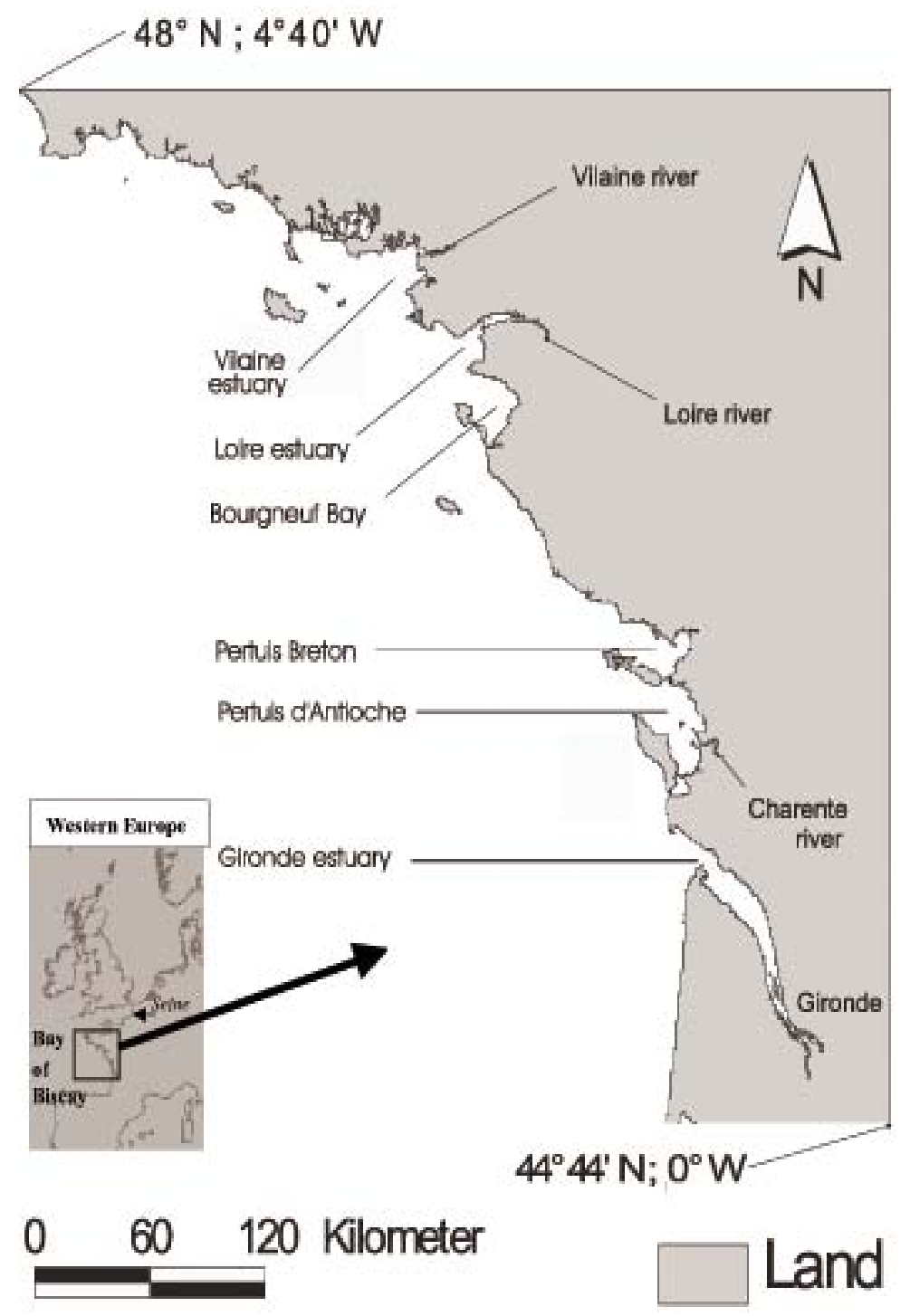

Fig. 1. Map of the central part of the Bay of Biscay showing the main rivers and common sole Solea solea nursery grounds. Inset lower left corner: the location of the Bay of Biscay in western Europe. 


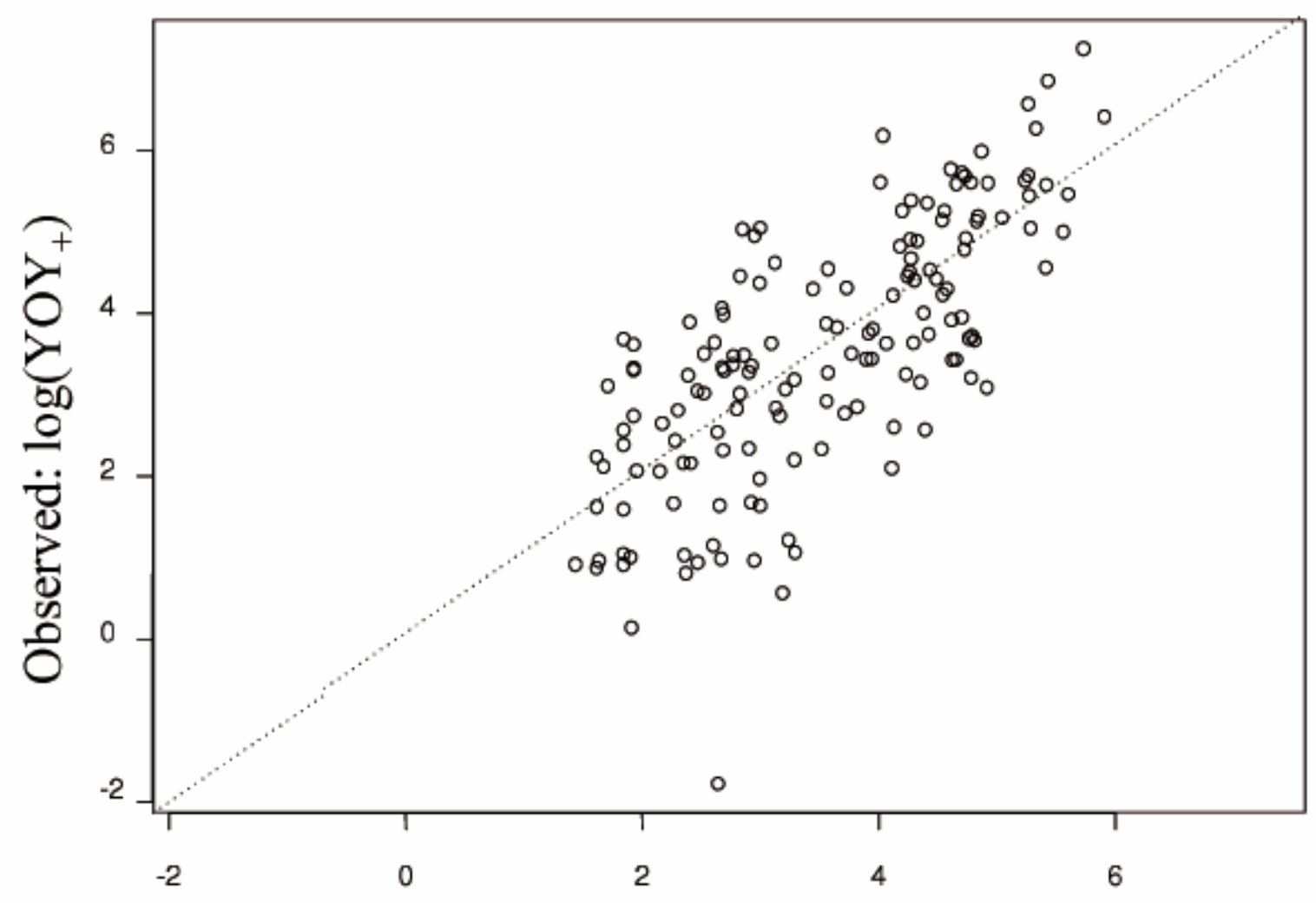

Fitted: $\log \left(\mathbf{Y O Y}_{+}\right) \sim$ nursery $\times$ bathymetry $\times$ sediment + deposit-suspensive feeder

Fig. 2. Log-transformed positive densities of young-of-the-year common sole Solea solea in survey data versus fitted values of the positive model using two descriptors:

Physics $\times$ Geography and logtransformed densities of deposit-suspension feeders. 

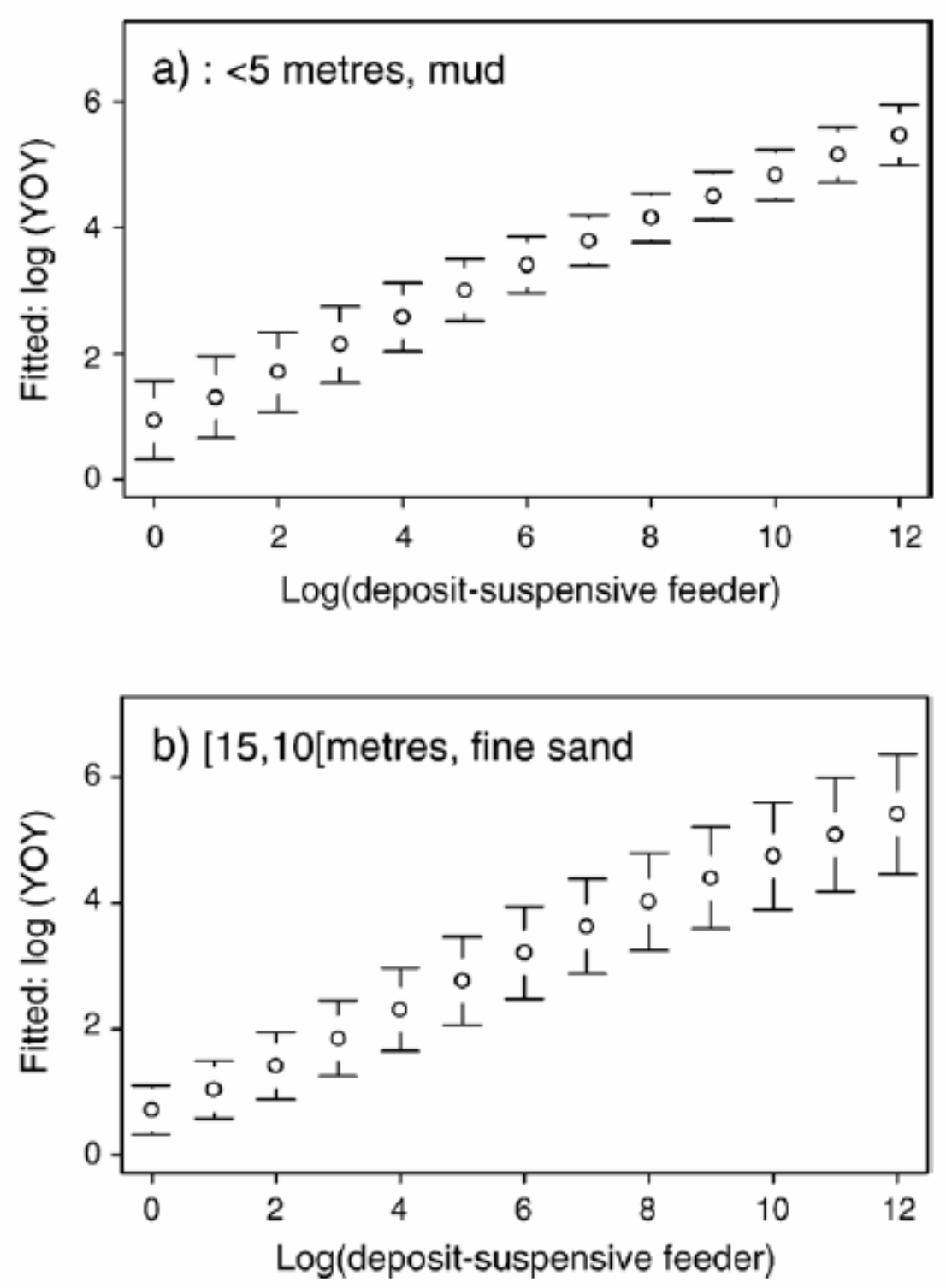

Fig. 3. Fitted log-transformed young-of-the-year common sole Solea solea abundance (calculated by delta model with Eq. (6), built with Eqs. (3) and (5) and associated confidence intervals (calculated with Eq. (7), for $\alpha=0.05$ ) in different physical habitats, with relation to the density of trawled epibenthic invertebrates that feed on detrital or planktonic organic matter. 
Table 1. Life history traits of the trawled invertebrate species (in this classification, species are pooled by genera when all the functional groups are the same inside).

\begin{tabular}{|c|c|c|c|c|c|c|c|}
\hline Name & Trophic group & $\begin{array}{l}\text { Relation } \\
\text { with sea }\end{array}$ & Mobility & Name & Trophic group & $\begin{array}{l}\text { Relation } \\
\text { with sea }\end{array}$ & $\begin{array}{c}\text { Mobilit } \\
y\end{array}$ \\
\hline ANNELIDA & & & & Cephalopoda & & & \\
\hline Aphrodita aculeata & Carnivorous & crawl-walk & medium & Alloteuthis spp. & Carnivorous & swimmer & high \\
\hline Maldanidae spp. & Deposit feeder & $\begin{array}{l}\text { sessile- } \\
\text { burrow }\end{array}$ & no & Loligo vulgaris & Carnivorous & swimmer & high \\
\hline Owenia fusiformis & Deposit feeder & $\begin{array}{l}\text { sessile- } \\
\text { burrow }\end{array}$ & no & Sepia officinalis & Carnivorous & swimmer & high \\
\hline Lagis koreni & Deposit feeder & $\begin{array}{l}\text { sessile- } \\
\text { burrow }\end{array}$ & low & Sepiola atlantica & Carnivorous & swimmer & high \\
\hline Sternaspis scutata & Deposit feeder & crawl-walk & low & ARTHROPODA & & & \\
\hline MOLLUSCS & & & & Amphipoda & & & \\
\hline Bivalva & & & & Haploops spp. & $\begin{array}{c}\text { Suspension } \\
\text { feeder }\end{array}$ & crawl-walk & low \\
\hline Abra spp. & Deposit feeder & $\begin{array}{l}\text { sessile- } \\
\text { burrow }\end{array}$ & no & Isopoda & & & \\
\hline \begin{tabular}{|l|} 
Acanthocardia \\
echinata
\end{tabular} & $\begin{array}{c}\text { Suspension } \\
\text { feeder }\end{array}$ & $\begin{array}{l}\text { sessile- } \\
\text { burrow }\end{array}$ & no & Idotea spp. & Scavenger & crawl-walk & medium \\
\hline \begin{tabular}{|l|} 
Aequipecten \\
opercularis
\end{tabular} & $\begin{array}{l}\text { Suspension } \\
\text { feeder }\end{array}$ & swimmer & low & Stomatopoda & & & \\
\hline Cerastoderma edule & $\begin{array}{c}\text { Suspension } \\
\text { feeder }\end{array}$ & $\begin{array}{l}\text { sessile- } \\
\text { burrow }\end{array}$ & no & Rissoides desmaresti & Carnivorous & $\begin{array}{l}\text { sessile- } \\
\text { burrow }\end{array}$ & medium \\
\hline Chamelea striatula & Suspension & sessile- & no & Decapoda & & & \\
\hline Chlamys varia & $\begin{array}{l}\text { Suspension } \\
\text { feeder }\end{array}$ & $\begin{array}{l}\text { sessile- } \\
\text { burrow }\end{array}$ & no & $\begin{array}{l}\text { Anapagurus } \\
\text { hyndmanni }\end{array}$ & Deposit feeder & crawl-walk & low \\
\hline Corbula gibba & $\begin{array}{c}\text { Suspension } \\
\text { feeder }\end{array}$ & $\begin{array}{l}\text { sessile- } \\
\text { burrow }\end{array}$ & no & $\begin{array}{l}\text { Asthenognathus } \\
\text { atlanticus }\end{array}$ & Deposit feeder & crawl-walk & low \\
\hline Crassostrea gigas & $\begin{array}{c}\text { Suspension } \\
\text { feeder }\end{array}$ & $\begin{array}{l}\text { sessile- } \\
\text { burrow }\end{array}$ & no & $\begin{array}{l}\text { Atelecyclus } \\
\text { undecimdentatus }\end{array}$ & Carnivorous & crawl-walk & high \\
\hline Donax vittatus & $\begin{array}{c}\text { Suspension } \\
\text { feeder }\end{array}$ & $\begin{array}{l}\text { sessile- } \\
\text { burrow }\end{array}$ & no & Cancer pagurus & Carnivorous & crawl-walk & high \\
\hline Ensis siliqua & $\begin{array}{l}\text { Suspension } \\
\text { feeder }\end{array}$ & $\begin{array}{l}\text { sessile- } \\
\text { burrow }\end{array}$ & no & Carcinus maenas & carnivorous & crawl-walk & high \\
\hline Glycymeris glycymeris & $\begin{array}{c}\text { Suspension } \\
\text { feeder }\end{array}$ & $\begin{array}{l}\text { sessile- } \\
\text { burrow }\end{array}$ & no & \begin{tabular}{|l|} 
Corystes \\
cassivelaunus
\end{tabular} & $\begin{array}{c}\text { Suspension } \\
\text { feeder }\end{array}$ & $\begin{array}{l}\text { sessile- } \\
\text { burrow }\end{array}$ & high \\
\hline Laevicardium crassum & $\begin{array}{l}\text { Suspension } \\
\text { feeder }\end{array}$ & $\begin{array}{l}\text { sessile- } \\
\text { burrow }\end{array}$ & no & Crangon crangon & Carnivorous & swimmer & high \\
\hline Lucinidae spp. & $\begin{array}{l}\text { Suspension } \\
\text { feeder }\end{array}$ & $\begin{array}{l}\text { sessile- } \\
\text { burrow }\end{array}$ & no & Diogenes pugilator & Deposit feeder & crawl-walk & low \\
\hline Lutraria spp. & $\begin{array}{c}\text { Suspension } \\
\text { feeder }\end{array}$ & $\begin{array}{l}\text { sessile- } \\
\text { burrow }\end{array}$ & no & Ebalia tuberosa & Deposit feeder & crawl-walk & low \\
\hline Macoma balthica & $\begin{array}{l}\text { Suspension } \\
\text { feeder }\end{array}$ & $\begin{array}{l}\text { sessile- } \\
\text { burrow }\end{array}$ & low & Eurynome spinosa & Carnivorous & crawl-walk & low \\
\hline Mactra stultorum & $\begin{array}{c}\text { Suspension } \\
\text { feeder }\end{array}$ & $\begin{array}{l}\text { sessile- } \\
\text { burrow }\end{array}$ & no & Inachus spp. & Carnivorous & crawl-walk & low \\
\hline Myrtea spinifera & $\begin{array}{l}\text { Suspension } \\
\text { feeder }\end{array}$ & $\begin{array}{l}\text { sessile- } \\
\text { burrow }\end{array}$ & no & Liocarcinus spp. & Carnivorous & crawl-walk & high \\
\hline Mysia undata & Deposit feeder & $\begin{array}{l}\text { sessile- } \\
\text { burrow }\end{array}$ & no & Macropodia spp. & Carnivorous & crawl-walk & low \\
\hline Mytilus edulis & $\begin{array}{l}\text { Suspension } \\
\text { feeder }\end{array}$ & $\begin{array}{l}\text { sessile- } \\
\text { burrow }\end{array}$ & no & Maja brachydactyla & Carnivorous & crawl-walk & high \\
\hline Nucula spp. & Deposit feeder & $\begin{array}{l}\text { sessile- } \\
\text { burrow }\end{array}$ & no & Necora puber & Carnivorous & swimmer & high \\
\hline Ostrea edulis & $\begin{array}{l}\text { Suspension } \\
\text { feeder }\end{array}$ & $\begin{array}{l}\text { sessile- } \\
\text { burrow }\end{array}$ & no & Paguridae spp. & Scavenger & crawl-walk & medium \\
\hline Pandora inaequivalvis & $\begin{array}{l}\text { Suspension } \\
\text { feeder }\end{array}$ & $\begin{array}{l}\text { sessile- } \\
\text { burrow }\end{array}$ & no & Palaemon spp. & Deposit feeder & swimmer & high \\
\hline Pecten maximus & $\begin{array}{l}\text { Suspension } \\
\text { feeder }\end{array}$ & swimmer & low & Crangon trispinosus & Carnivorous & swimmer & high \\
\hline Pharus legumen & $\begin{array}{l}\text { Suspension } \\
\text { feeder }\end{array}$ & $\begin{array}{l}\text { sessile- } \\
\text { burrow }\end{array}$ & no & Pisidia longicornis & $\begin{array}{l}\text { Suspension } \\
\text { feeder }\end{array}$ & crawl-walk & low \\
\hline Phaxas pellucidus & Suspension & sessile- & no & Polybius henslowii & Carnivorous & swimmer & high \\
\hline
\end{tabular}




\begin{tabular}{|c|c|c|c|c|c|c|c|}
\hline & feeder & burrow & & & & & \\
\hline Pholas dactylus & $\begin{array}{l}\text { Suspension } \\
\text { feeder }\end{array}$ & $\begin{array}{l}\text { sessile- } \\
\text { burrow }\end{array}$ & no & Porcellana platycheles & $\begin{array}{l}\text { Suspension } \\
\text { feeder }\end{array}$ & crawl-walk & low \\
\hline Spisula spp. & $\begin{array}{l}\text { Suspension } \\
\text { feeder }\end{array}$ & $\begin{array}{l}\text { sessile- } \\
\text { burrow }\end{array}$ & no & Spiropagurus elegans & Scavenger & crawl-walk & low \\
\hline Tellina fabula & $\begin{array}{c}\text { Suspension } \\
\text { feeder }\end{array}$ & $\begin{array}{l}\text { sessile- } \\
\text { burrow }\end{array}$ & no & ECHINIDERMATA & & & \\
\hline Gastropoda & & & & Asteroida & & & \\
\hline Acteon tornatilis & Carnivorous & crawl-walk & medium & Asterias rubens & Carnivorous & crawl-walk & medium \\
\hline Aplysia spp. & Grazer & crawl-walk & low & \begin{tabular}{|l|} 
Astropecten irregularis \\
irregularis
\end{tabular} & Carnivorous & crawl-walk & medium \\
\hline Aporrhais pespelecani & Carnivorous & crawl-walk & low & Marthasterias glacialis & Carnivorous & crawl-walk & medium \\
\hline Armina loveni & Carnivorous & crawl-walk & low & Echinoidea & & & \\
\hline Buccinum undatum & Scavenger & crawl-walk & medium & \begin{tabular}{|l|} 
Echinocardium \\
cordatum
\end{tabular} & Deposit feeder & $\begin{array}{l}\text { sessile- } \\
\text { burrow }\end{array}$ & low \\
\hline $\begin{array}{l}\text { Calliostoma } \\
\text { zizyphinum }\end{array}$ & Grazer & crawl-walk & low & $\begin{array}{l}\text { Psammechinus } \\
\text { miliaris }\end{array}$ & Grazer & crawl-walk & low \\
\hline Crepidula fornicata & $\begin{array}{c}\text { Suspension } \\
\text { feeder }\end{array}$ & $\begin{array}{l}\text { sessile- } \\
\text { burrow }\end{array}$ & no & Holothurida & & & \\
\hline Euspira spp. & Carnivorous & crawl-walk & low & $\begin{array}{l}\text { Leptopentacta } \\
\text { elongata }\end{array}$ & $\begin{array}{c}\text { Suspension } \\
\text { feeder }\end{array}$ & $\begin{array}{l}\text { sessile- } \\
\text { burrow }\end{array}$ & low \\
\hline Gibbula spp. & Grazer & crawl-walk & low & $\begin{array}{l}\text { Leptosynapta } \\
\text { inhaerens }\end{array}$ & Grazer & $\begin{array}{l}\text { sessile- } \\
\text { burrow }\end{array}$ & low \\
\hline Nassarius reticulatus & Scavenger & crawl-walk & medium & Ophiuroidea & & & \\
\hline Nucella lapillus & Carnivorous & crawl-walk & Iow & Amphiura spp. & $\begin{array}{c}\text { Suspension } \\
\text { feeder }\end{array}$ & crawl-walk & low \\
\hline Ocenebra erinaceus & Carnivorous & crawl-walk & low & Ophiothrix fragilis & $\begin{array}{c}\text { Suspension } \\
\text { feeder }\end{array}$ & $\begin{array}{l}\text { sessile- } \\
\text { burrow }\end{array}$ & low \\
\hline Philine aperta & Carnivorous & crawl-walk & medium & Ophiura spp. & Carnivorous & crawl-walk & low \\
\hline Trivia monacha & Carnivorous & crawl-walk & low & & & & \\
\hline Turritella communis & $\begin{array}{c}\text { Suspension } \\
\text { feeder }\end{array}$ & crawl-walk & low & & & & \\
\hline \multicolumn{8}{|l|}{ Scaphopoda } \\
\hline Antalis spp. & Deposit feeder & $\begin{array}{l}\text { sessile- } \\
\text { burrow }\end{array}$ & no & & & & \\
\hline
\end{tabular}


Table 2. Correlation coefficients $(r)$ between the functional groups used to describe benthic fauna. High values are highlighted in bold.

\begin{tabular}{|c|c|c|c|c|c|c|c|c|c|c|c|c|}
\hline & 1 & 2 & 3 & 4 & 5 & 6 & 7 & 8 & 9 & 10 & 11 & 12 \\
\hline $\begin{array}{l}\text { 1- Carnivorous } \\
\text { 2- Deposit feeders }\end{array}$ & $\begin{array}{c}1 \\
0,75\end{array}$ & 1 & & & & & & & & & & \\
\hline $\begin{array}{l}\text { 3- Suspension } \\
\text { feeders }\end{array}$ & 0,62 & 0,57 & 1 & & & & & & & & & \\
\hline 4- Grazers & $-0,01$ & $-0,05$ & 0,10 & 1 & & & & & & & & \\
\hline 5- Necrophagous & 0,43 & 0,32 & 0,47 & 0,09 & 1 & & & & & & & \\
\hline $\begin{array}{l}\text { 6- Sessile } \\
\text { burrowers }\end{array}$ & 0,74 & 0,86 & 0,76 & $-0,07$ & 0,37 & 1 & & & & & & \\
\hline 7- Crawlers-walkers & 0,92 & 0,74 & 0,70 & 0,02 & 0,57 & 0,75 & 1 & & & & & \\
\hline 8- Swimmers & 0,47 & 0,35 & 0,10 & $-0,01$ & 0,06 & 0,27 & 0,28 & 1 & & & & \\
\hline 9- No mobility & 0,75 & 0,81 & 0,79 & $-0,03$ & 0,40 & 0,97 & 0,78 & 0,24 & 1 & & & \\
\hline 10- Low mobility & 0,86 & 0,77 & 0,68 & 0,04 & 0,53 & 0,79 & 0,93 & 0,21 & 0,78 & 1 & & \\
\hline 11- Med. mobility & 0,65 & 0,52 & 0,60 & 0,02 & 0,81 & 0,59 & 0,77 & 0,20 & 0,61 & 0,72 & 1 & \\
\hline 12- High mobility & 0,55 & 0,45 & 0,14 & $-0,07$ & 0,06 & 0,36 & 0,38 & 0,90 & 0,33 & 0,30 & 0,22 & 1 \\
\hline
\end{tabular}

Table 3. Analysis of deviances for the two parts of the 4 delta log-normal Generalized Linear Model testing for the explanation of $y-0-y$ by the 4 trophic groups. Columns indicate residual degrees of freedom (DoF), confidence level of the test $\left(p\left(\chi^{2}\right)\right)$ and deviance explained by the variable when significant at a $5 \%$ level (Deviance, in \%)

\begin{tabular}{|c|c|c|c|c|c|c|}
\hline & \multicolumn{3}{|c|}{ Binomial model $\left(\mathrm{YOY}_{0 / 1}\right)$} & \multicolumn{3}{|c|}{ Positive value model $\left(\mathrm{YOY}_{+}\right)$} \\
\hline Added variable & DoF & $p\left(\chi^{2}\right)$ & Deviance & DoF & $p\left(\chi^{2}\right)$ & Deviance \\
\hline Null & 190 & & & 149 & & \\
\hline Model : YOY log-tr & ed dens & in one of & four trophic $\mathrm{g}$ & & & \\
\hline deposit-suspension & 189 & $10^{-11}$ & 23.2 & 137 & 0 & 34.6 \\
\hline $\begin{array}{l}\text { fnadderorous } \\
\text { carnivorous }\end{array}$ & 189 & $3.10^{-15}$ & 31.4 & 137 & $10^{-14}$ & 16.2 \\
\hline grazers & 189 & $>0.05$ & non-significant & 137 & $>0.05$ & non- \\
\hline necrophagous & 189 & $>0.05$ & non-significant & 137 & $>0.05$ & non- \\
\hline
\end{tabular}


Table 4. Analysis of deviances for the two parts of the delta log-normal Generalized Linear Model. Columns indicate residual degrees of freedom (DoF), Akaike information criterion (AIC), explained deviance for each added variable when significant at a $5 \%$ level (Deviance, in \%) and explained deviance of the model (Expl. Deviance, in \%, sum of the deviance for the descriptors)

\begin{tabular}{|c|c|c|c|c|c|c|c|c|}
\hline & \multicolumn{4}{|c|}{ Binomial model $\left(\mathrm{YOY}_{0 / 1}\right)$} & \multicolumn{4}{|c|}{ Positive value model (YOY+) } \\
\hline Added variable & DoF & AIC & Deviance & $\begin{array}{c}\text { Expl. } \\
\text { Deviance }\end{array}$ & DoF & AIC & Deviance & $\begin{array}{c}\text { Expl. } \\
\text { Deviance }\end{array}$ \\
\hline Null & 190 & 193 & & & 149 & 347,7 & & \\
\hline \multicolumn{9}{|c|}{ First model : YOY Physics $\times$ Geography + Benthic fauna (Eqs. 2\&4) } \\
\hline $\begin{array}{l}\text { nursery } \times \text { bathymetry } \times \text { sedim } \\
\text { ent }\end{array}$ & 179 & 161 & 33,4 & & 138 & 247 & 43,1 & \\
\hline \multicolumn{9}{|c|}{ YOY nursery $\times$ bathymetry $\times$ sediment + deposit-suspension feeder } \\
\hline deposit-suspension feeders & 178 & & $\begin{array}{c}\text { non- } \\
\text { significant }\end{array}$ & & 137 & 213,1 & 10 & 53,1 \\
\hline \multicolumn{9}{|c|}{ YOY nursery $\times$ bathymetry $\times$ sediment + carnivorous } \\
\hline carnivorous & 178 & 141,8 & 10,3 & 43,7 & 137 & 238,6 & 3,1 & 46,2 \\
\hline \multicolumn{9}{|c|}{ Second model : YOY Physics + Benthic fauna (Eqs. 3\&5) } \\
\hline bathymetry $\times$ sediment & 187 & 199,1 & 10,8 & & 146 & 326,4 & 16,3 & \\
\hline \multicolumn{9}{|c|}{ sole $\sim$ bathymetry $\times$ sediment + deposit-suspension feeder } \\
\hline deposit-suspension feeders & 186 & 176,3 & 12,7 & 23,5 & 145 & 244,2 & 23,4 & 39,7 \\
\hline \multicolumn{9}{|c|}{ sole $\sim$ bathymetry $\times$ sediment + carnivorous } \\
\hline carnivorous & 186 & 155,6 & 22,6 & 33,4 & 145 & 297 & 9,1 & 25,4 \\
\hline
\end{tabular}

